\title{
LITERATURA ÁRABE Y LITERATURA FRANCESA EN LA EDAD MEDIA
}

\author{
Por \\ ÁLVARO GALMÉS DE FUENTES
}

Con frecuencia se han señalado influencias de la literatura árabe en la literatura española, aunque muchas veces se han aceptado tales influjos con reticencia o incluso han sido negados.

A pesar de todo, y elevando aún más el tiro, creo que la influencia del árabe en la edad media no se limita a España o a Sicilia, las dos zonas europeas que estuvieron dominadas por los árabes, sino que, se quiera o no, Europa entera en la edad media estuvo dentro de la órbita cultural árabe entonces superior a la occidental.

A veces he dicho, medio en broma, a algunos colegas franceses que, en el medioevo, África no empieza en los Pirineos, sino cuando menos en el Rin, y, en uno de sus últimos trabajos, Paul Zumthor repite esta afirmación conmigo, pero extendiendo hasta el Elba o más allá la frontera africana (1).

Sin embargo se debe insistir sobre esta cuestión, porque a muchos eruditos les cuesta aceptar las posibles relaciones entre la cultura árabe y la cultura europea, aunque ello implica una contradicción respecto a la dialéctica histórica. Es inconcebible, en efecto, que la civilización árabe, muy superior a la europea del medioevo, no haya dejado ninguna huella en tantos siglos de convivencia directa o tangencial. $\mathrm{Ne}$ gando este posible influjo, no sólo se comete una injusticia con relación al mundo árabe, considerado así como incapaz de proyectar su riqueza cultural sobre los otros pueblos con los que ha convivido largamente, sino que se desprecia, al mismo tiempo, a la Europa medieval, ciega frente a los tesoros culturales depositados ante sus ojos, e incapaz de comprender y asimilar tanta riqueza.

El prejuicio antiárabe, que todavía ofusca a muchos estudiosos, se basa en la

(1) P. ZUMTHOR: La lettre et la voix (De la «fittérature» médiévale). Paris, 1987, págs. 33-34. 
falsa creencia de la no comunicación del mundo cristiano con el mundo musulmán. Sin entrar ahora en polémica, recordaré cómo Menéndez Pidal señala dos hechos fundamentales en la historia cultural del Occidente ocurridos en la primera mitad del s. XII, hechos que testimonian la fuerza expansiva de la cultura árabe: un judio converso de Aragón traducia al latín del árabe una colección de cuentos orientales, y su obra, titulada Disciplina clericalis, fue durante varios siglos fuente de inspiración para los cuentistas del mundo occidental, y en sus aguas bebieron los tres máximos representantes del género: don Juan Manuel en España, Boccaccio en Italia y Chaucer en Inglaterra; por los mismos años aproximadamente, a partir del año 1130, el arzobispo don Raimundo de Toledo y el arcediano Gundisalvo de Segovia fundan la conocida escuela toledana de traductores, transfiriendo al mundo europeo el caudal científico árabe (astronomia, matemática, botánica, física, filosofía), que causó el asombro de los escolásticos. Teniendo en cuenta, a título de ejemplo, estos dos grandes sucesos culturales, es imposible negar en un ámbito mucho más amplio las estrechas relaciones entre la literatura árabe y la románica en general.

Habida cuenta de las circunstancias anteriores, voy a señalar aquí, a modo de ejemplo, algunos casos concretos de la influencia de la literatura árabe en la literatura románica de allende el Pirineo.

No voy a tratar aquí del problema de la lírica románica en relación con la lírica árabe, problema ampliamente debatido, y en el que intervienen aspectos discutibles en los que puede operar la subjetividad del crítico. Por eso prefiero limitarme ahora a un análisis comparativo de términos que presentan, a mi juicio, un carácter más objetivo, como ocurre generalmente en la literatura narrativa.

Respecto a la épica, en otra ocasión he señalado una serie de motivos temáticos que, según creo, han pasado desde la narrativa épico-caballeresca árabe a los cantares de gesta románicos (españoles, franceses o galo-itálicos) (2). No voy a insistir aquí sobre esa cuestión. De otro lado, son frecuentes los cantares de gesta franceses en relación con temática hispánica o andalusí. En Toledo, por ejemplo, se escribió, como señala R. Menéndez Pidal, la famosa gesta francesa del Mainet o «Mocedades de Carlomagno», a la cual se transfieren, referidos al emperador francés, episodios de la leyenda árabe sobre los amores de Alfonso VI de Castilla y la mora Zaida, lo mismo que en la versión franco-italiana designada con el título de Karleto (3). La gesta del Anseis de Cartage reelabora la leyenda española de la pérdida de España en la época del rey Rodrigo (4), leyenda que a su vez era, sin duda, de origen árabe (5). A través del Anseīs la leyenda andalusí emigró a Italia, en donde, en

(2) Véase ÁLVARO GALMÉS DE FUENTES: «Épica árabe y épica castellana (Problema crítico de sus posibles reiaciones), en Atti del convegno internazionale sul tema: La poesia epica e la sua formazione (Roma: Accademia Nazionale dei Lincei, 1970). Véase ahora, ÁLVARO GALMÉS DE FUENTES, Epica árabe y épica castellana (Barcelona: Editorial Ariel, 1978)

(3) R. MENÉNDEZ PIDAL: Historia y epopeya, Madrid, 1934, págs. 267-284

(4) Ibid., p. 282; H. BRETT-SCHNEIDER: Der "Ansel de Cartage» und die «Seconda Spagna», Halle, 1937, pp. 31-53; E. VON RICHTHOFEN: Estudios épicos medievales, Madrid, 1954, pp. 71-73; ibid., Nuevos estudios épicos medievales, Madrid, 1970, p. 22; M. DEFOURNEAUX: Les Français en Espagne aux Xle et XIle siècle, Paris, 1949, pp. 282-283.

(5) Cfr. H. KRAPPE: «Une version orientale de la légende de Rodrigue, dernier roi visigoth», en Bulletin Hispanique, XVill, 1926, pp. 176-179. 
el siglo XV, inspiró La Seconda Spagna. La relación es evidente entre el tema del cantar de gesta francés de Galliens li Restoré y el de la leyenda castellana de los Infantes de Salas, en lo que concierne al bastardo Mudarra (6), y los dos motivos están en relación con la tradición musulmana (7). Citaré finalmente otros cantares de gesta franceses cuya fuente, según el ilustre romanista alemán E. von Richthofen, es en gran parte hispano-árabe, como L'Entrée en Espagne, la Prise de Pampelune, la Siège de Barbastre, Guibert d'Andrenas, la Prise de Cordre et de Sebille, Folque de Candie, Gui de Bourgogne, la Chanson d'Otinel, ATol et Mirabel, etc. (8). La misma Chanson de Roland, sino fue escrita en España como quiere J.C. Rusell (9), ha sido, según diversos investigadores, inspirada indudablemente por la historia y la leyenda de Alfonso $V I$ transpuesta sobre un fondo carolingio, opinión sostenida con insistencia por A. de Mandach. Este último pone de relieve la circunstancia, de especial interés a nuestro propósito, según la cual la historia alfonsí, más o menos legendaria, que se encuentra en la poesía épica carolingia, no está vista según las fuentes cristianas sino árabes:

«Pour comprendre le substrat des récits épiques il faut avant tout consulter les textes arabes» (10). «Plus on examine les épisodes de la vie d'Alphonse VI, selon les chroniques arabes, plus on y relève de parallèles avec des gestes roncevalliennes» (11).

Y los juglares que componian o reelaboraban gestas francesas tenían plena conciencia de esta impronta hispánica o andalusí. Así, por ejemplo, Adenet le Roi afirma explícitamente al fin de sus Cléomades, obra unánimemente considerada de origen árabe:

v. 10509 Se vos savoir en voulez

plus avant, en Espaigne alez,

ou à Toulete ou à Sebile.

Je ne sai pas en laquele vile

de ces II plus tost trouveriez

l'estoire, se la querries (12).

O el autor anónimo del poema épico de Amis et Amile, alabándose de la veracidad de los hechos que relata, se expresa así al comienzo del cantar:

v. 1 Or entendez, signor gentil baron;

De tel barnaige doit on dire chanson.

Ce n'est pas fable que dire vos volons, ansoiz est voirs autressi com sermon,

(6) R. MENÉNDEZ PIDAL: La leyenda de los infantes de Lara, Madrid, 1934, pp. 19-20, 32-33.

(7) Á. GALMÉS DE FUENTES: Épica árabe... pp. 102-103; ÁLVARO GALMÉS DE FUENTES: «La leyenda de los infantes de Salas y la tradición árabem, en Actas de las Jornadas de Cultura Arabe e /slámica, Madrid, 1981, pp. 365-388.

(8) E. VON RICHTHOFEN: Nuevos estudios épicos..., pp. 30-46, 147-149.

(9) J.C. RUSSELL: "The "chanson de Roland"; written in Spain in 1033?", en Stud. in Philol., XLIX, 1952, pp. 17-24

(10) A. DE MANDACH: Naissance et développement de la chanson de geste en Europe. l: La geste de Charlema. ge et de Roland, Paris/Genève, 1961, p. 35

(11) Ibid., p. 38.

(12) Cléomadès, ed. J. MARCHAND, Paris, 1925. 
car plusors gens a tesmoing en traionz, clers et prevoires, gens de religion.

Li pelerin qui a Saint Jaque vont

le seven bien, se ce est voirs ou non (13).

Y efectivamente, este célebre poema épico de Amis et Amile está íntimamente relacionado con la tradición árabe, como voy a tratar de demostrar rápidamente. Para ofrecer una versión imparcial, he aquí el resumen que realiza Martín de Riquer de dicho poema épico:

«Amis y Amile nacen el mismo dia físicamente casi idénticos, en países diferentes, pero se encuentran los dos en la corte sirviendo a Carlomagno, donde se juran amistad. Andando el tiempo, Amis llega a ser conde de Blaye, y se retira a su castillo; Amile se convierte en el amante de Bélissent, hija de Carlomagno, lo que es descubierto y denunciado por el traidor Hardré. Se decide organizar un duelo judicial para descubrir la verdad, pero Amile, sabiendo con seguridad que es cierta la acusación, y que, consecuentemente, será vencido al tiempo que Bélissent quedará deshonrada, se deja reemplazar en el duelo por Amis, que ha acudido en ayuda de su amigo. Amile huye a Blaye, sustituyendo a su camarada, y Amis resulta vencedor en el combate y mata a Hardré, pero se ve obligado a casarse con Bélissent, pecado por el que será castigado por Dios. Así, parte con ella hacia Blaye a fin de entregarla a Amile, su verdadero amante. Amis paga con la lepra su pecado, lo que le obliga a andar errante como un mendigo hasta que llega al castillo de Amile, quien atiende solícito a Amis hasta que un día conoce, por la revelación divina de un ángel, que podrá curar a su amigo si le baña con la sangre inocente de sus propios hijos. Amile no duda, degüella a sus hijos, y cura la lepra de su amigo, pero entonces se produce un nuevo milagro y resucitan los niños. Más tarde Amis y Amile mueren el mismo dian (14).

Se han buscado para esta leyenda antecedentes folclóricos lejanos en los dominios gérmanico (15), hindú (16) y celta (17), e incluso en la tradición clásica del culto a Cástor y Pollux (18), y J. Bédier, que localiza la leyenda en el monasterio de San Albino de Mortara, en el norte de Italia, concluye, siguiendo su teoría general, que la leyenda de Amis et Amile fue una creación de los monjes de San Albino, quienes proporcionaron sus datos a los juglares que recorrían la ruta de los peregrinos franceses a Roma (19).

Pero la realidad es a mi juicio muy diferente, y sin duda mucho más sencilla. La leyenda de Amis y Amile se encuentra ya en la Historia de los Siete Sabios de Roma, que reproduce, con amplificaciones, el Sendebar, cuya versión árabe aparece citada en el siglo X por Mas'ūdi en sus Praderas de Oro, e inserta en las Mil y una noches. La versión más antigua que se conserva es la española, mandada hacer por el infante don Fadrique, en 1253, de un original árabe.

He aquí el resumen de la versión de la Historia de los Sabios de Roma:

(13) Ami et Amile, ed. P.F. DEMBOWSKI, Paris, 1969 ("C.F.M.A.»).

(14) MARTIN DE RIQUER: Les chansons de geste françaises, París, 1968, p. 270.

(15) Cfr. P. SCHWIEGER: Die Sage von Amis und Amiles, Berlín, 1885.

(16) Cir. G. HUET: "Amis et Amile, les origines de la légendes, en Le Moyen Âge, XXXI, 1919, pp. $162-186$.

(17) F. BAR: Les Epitres latines de Raoul le Tourtier. Étude de sources. La legende d'Ami et d'Amile, Paris, 1937

(18) Cfr. A.H. KRAPPE: "The Legend of Amicus", en Modern Language Review, XVIll, 1932, pp. 152-161.

(19) Cfr. J. BÉDIER: Les légendes épiques, 2. ${ }^{a}$ ed., vol. Il, París, 1917, pp. 178-206. 


\begin{abstract}
Alexandre, hijo del rey de Egipto, y Luis, hijo del rey de Francia, se encuentran en la corte sirviendo al emperador Titos, "que a todos los reyes del mundo en linaje e cortesía sobrava». Ambos amigos, que se juran amistad, "parecianse tanto en el gesto e rostro e costumbres que a mala vez podían distinguir el uno del otrom. Andando el tiempo Alexandre, por muerte de su padre, es nombrado rey de Egipto, teniendo que abandonar la corte del emperador Titos, mientras que Luis se convierte en el amante de Florentina, hija del emperador, lo que es descubierto y denunciado por Guido, hijo del rey de España, que se halla en la corte del emperador sustituyendo a Alexandre. Ante la denuncia se decide organizar un duelo judicial para descubrir la verdad, pero Luis, sabiendo que es cierta la acusación y que, en consecuencia, será vencido, por consejo de Florentina va a Egipto a buscar a su amigo Alexandre para que le sustituya en el duelo, mientras Luis regirá los destinos de Egipto. Alexandre resulta vencedor en el combate y mata a Guido; después vuelve a Egipto para relevar a Luis, que regresa a la corte de Titos, sin que nadie, salvo Florentina, haya echado de menos su ausencia. Pero Alexandre, por malquerencia de su mujer adúltera, es emponzoñado, con lo que se vuelve leproso. Arrojado del reino, se ve obligado a andar errante como un mendigo hasta que llega al castillo de Luis, ya convertido en rey de Francia por muerte de su padre. Luis le atiende solícito hasta que un día conoce, por revelación divina, que podrá curar a su amigo si lavara su cuerpo con la sangre inocente de sus propios hijos. Luis no duda, degüella a sus dos hijos y limpia la lepra de su amigo, pero entonces «Dios, por su infinita bondad, quiso mostrar otro gran milagro: que quando fueron a la cámara, oyeron cantar a los niños la Salve Regina» (20).
\end{abstract}

Como puede observarse, la historia es idéntica en los dos relatos. Ahora bien, como esta leyenda de los dos amigos no aparece en la versión del Sendebar, traducida del árabe por encargo de don Fadrique, se ha supuesto, por algún crítico, como un aditamento de origen occidental en la Historia de los Siete Sabios. Sin embargo, aunque en versiones árabes tardías, de los siglos XIV y XV, Chauvin, en los números 234 y 35 , señala la presencia de nuestra leyenda, que tuvo difusión en el folclore árabe, pues hoy día reaparece en un cuentecillo bereber, cuyo origen nunca puede ser occidental sino necesariamente árabe. En este cuento, como es lógico, el ambiente heroico y feudal, es sustituido por un ambiente burgués, siendo los dos protagonistas un comerciante y un barbero, a quien aquél, haciéndose pasar por el ángel de la muerte, consigue que una viuda entregue en matrimonio a su hija al barbero, cuyo amor por aquella parecia imposible de alcanzar. Vuelto leproso el comerciante, el barbero sacrifica a su propio hijo, que finalmente reaparece sano y salvo (21).

Recordemos todavía que en Marruecos existe aún la creencia de que la lepra se puede curar con la sangre inocente de un niño sano, creencia que se refleja tam. bién en un cuento derviche, publicado por Idris Shah y titulado La cura con sangre humana, en el que se refiere que en tiempos del gran Imperio de Bizancio, uno de sus emperadores cayó enfermo de un terrible mal que nadie podía curar, hasta que un sufí aconsejó a los nobles del imperio que el mejor remedio sería que el emperador hiciera uso de su fe, a lo que le respondieron los nobles que el emperador tenía fe, pero que ella no había conseguido efectos terapeúticos. «En ese caso - dijo el sufí- un baño en la sangre de muchos niños menores de siete años curará al emperador». Pero éste rechazó, en un principio, tal propuesta hasta que le forzaron los

(20) Véase A. GONZÁLEZ PALENCIA: Versiones castellanas del «Sendebar», Madrid-Granada, 1946, pp. 237-273.

(21) E. LAOUST: Contes berberes du Maroc, vol. If, París, 1949, pp. 231-234. 
nobles, haciéndole creer que la sangre de unos cuantos niños valía menos que todo el imperio que, con su muerte, sucumbiría. Cuando fueron reunidos en Constantinopla los niños al efecto, el emperador se rebeló definitivamente y dio a conocer un edicto: «Prefiero morir yo, antes de ver morir a los inocentes». Apenas hubo dicho ésto, su enfermedad comenzó a ceder, y pronto estuvo completamente restablecido. Puesto que no tuvo el emperador suficiente fe, algo equivalente a ella fue la causa de su salud (22).

El episodio dramático de la cura de la lepra mediante el baño de sangre de niños inocentes, tema central del cantar de gesta de Amis et Amile, es pues de origen oriental y no occidental, lo que prueba en definitiva la fuente de todo el relato.

En otro caso, y también a modo de ejemplo, podemos señalar otro cantar de gesta francés, El Charroi de Nimes, en relación con la tradición árabe (23).

El motivo temático esencial del Charroi de Nimes consiste, como es sabido, en la artimaña ideada por Guillermo de Orange para conquistar la ciudad inexpugnable de Nîmes: a tal fin coloca a sus guerreros en toneles, que ocupan una larga serie de carretas; de esta forma son introducidos en la ciudad enemiga, simulando mercancias, bajo la dirección del propio Guillermo, disfrazado de mercader. Una vez en la ciudad, y bajo consigna establecida, los guerreros salen de los toneles, dominando a los sarracenos de Nîmes, ciudad que cae en poder de Guillermo.

Este motivo temático del acarreo de guerreros, en toneles o sacos, simulando mercancias, y como fórmula noble en la actividad guerrera, es lugar común en la literatura narrativo-caballeresca árabe.

En la grandiosa epopeya persa de Firdusi, titulada Šăh Namé o Libro de los reyes, desde muy temprano incorporada a la literatura árabe, encontramos ya el tema de la artimaña del carretaje: El padre de Rustām alecciona así a su hijo: "Hoy ha llegado el día para tí de intentar un medio lleno de astucia; tú irás, disfrazado de mercader y con el corazón alegre, conduciendo una caravana de carros, llena de guerreros pero simulando mercancias en los sacos, y obrarás de tal forma que los guardianes de la ciudad no te reconozcan» (24). Posteriormente, el historiador árabe del siglo $X$ al-Ta $a^{\prime l}$ ibīi, recoge el motivo temático firdusiano, referido a la conquista de una ciudad de bronce (25). Andando el tiempo, en el siglo XIV, Ibn Jaldün, el mayor historiador árabe, sin ninguna duda, vuelve a recordar todavía este motivo temático, referido esta vez a la historia de los bereberes de Occidente (26). Pero esta leyenda tiene orígenes mucho más antiguos en el mundo árabe, ya que remonta a los tiempos de la Jahiliyya, o época preislámica. Referida a este periodo, el autor de la extraordinaria enciclopedia, titulada Kitāb al-Agānì o Libro de las canciones,

(22) IDRIES SHAH: Cuentos de los derviches, Barcelona, Buenos Aires, Méjico, 1985, pp. 101-103.

(23) Para más detalles, véase un trabajo mío anterior, «Le Charroi de Nimes et la tradition arabe», en Cahiers de Civilisation Médiévale, XXII, 1979, pp. 125-137.

(24) FIRDOUST: Le livre des rois, traducción al francés de J. MOHL, 1, Paris, 1876, pp. 290-293.

(25) AL-THA'ĀLIBI: Histoire des rois des Perses, edición H. Zotenberg, pp. 328-338.

(26) IBN KHALDOUN: Histoire des Berbères et des dynasties musulmanes de l'Afrique Septentrionale, trad. Baron De Slane, nueva edición P. Casanova, París, 1925, pp. 416-418. 
Abū al-Farāy al-Isfahānī, del siglo X, cuenta que Quçayr, visir de 'Amr Ibn 'Adī, rey preislámico de Hîra, aconseja a éste la estratagema del carretaje para arrebatar a Zabbā' o Zenobia su reino y su vida (27). Por la misma fecha aproximadamente, Mas'üđī, también del siglo $X_{1}$ en su obra de «varia lección», titulada Murūú al-dahab o Praderas de oro, recoge esta leyenda referida a la misma época y a los mismos personajes (28).

De otro lado, esta leyenda del carretaje se halla también difundida en varios tipos de literatura tradicional árabe. En primer lugar, aparece en el género denominado al-sira, voz árabe que significa «conducta, manera de vivir», es decir «gesta», y que hace referencia a las narraciones caballerescas tradicionales, nacidas al calor de los hechos heroicos. En la Sira de los Banü Hilāl encontramos este motivo temático (29). Finalmente en el folclore actual reaparece de nuevo el tema. René Basset recoge el cuento popular en el que se narra la estratagema de Sammär para la conquista de Samarqanda (30).

Este número de ejemplos que he acumulado, prueba la amplia difusión y la autoctonia del motivo temático en la literatura árabe, de la cual lo hubo de tomar, sin duda, la canción de gesta francesa del Charroi de Nimes, pues no es concebible pensar en un fenómeno de poligénesis. Pero es que además, en algunas de las leyendas árabes, existe un relevante detalle, que pone de relieve la dependencia de la canción de gesta francesa respecto al motivo temático árabe, a la vez que explica el discutido epiteto épico, au Court Nez, aplicado a Guillermo de Orange en la epopeya carolingia. El hecho ciertamente de que el conde francés fuese chato representa un rasgo irrelevante, que no justificaría, en ningún modo, un epíteto épico que por fuerza debe ser dignificador dado el carácter heroico de la epopeya. Por tal motivo, la crítica no ha sabido dar razón de tal mote atribuido a Guillermo de Orange. La explicación creo que viene dada dentro del contorno árabe en que se desarrolla, como he pretendido demostrar, la canción de gesta titulada Le Charroi de Nimes.

Efectivamente, en las leyendas árabes en que se narra la historia del visir Qusayr y de Zabbā' o Zenobia, transmitidas por el Kitāb al-Agäni, Mas'ūdi y Abü-l-Fidā, se cuenta que cuando Qusayr propone al rey de Hirra 'Amr la estratagema del carretaje, éste le objeta el riesgo de la operación, toda vez que, aunque disfrazado de mercader, sería reconocido por la reina Zabbä; ante lo cual Qusayr propone al rey de Hîra que le corte la nariz, pero 'Amr se niega a infringir una mutilación infamante a su vasallo preferido, y entonces Qusayr, en rasgo heroico, se corta él mismo la nariz. $Y$ esta mutilación no tiene como finalidad únicamente la desfiguración del rostro, sino, en especial, el presentarse ante el enemigo, no como un guerrero afamado, sino como un facineroso, habida cuenta del significado penal que las mutilaciones corporales (de narices, orejas o manos) tienen en el derecho árabe de la jahiliyya y consecuentemente en el musulmán.

(27) KITAB AL-AGANII, ed. Bulaq, 1868-9, vol. XIV, pp. 74-75

(28) AL-MAS'UDT: Les prairies d'or, ed. y trad. C. BARBIER DE MEYNARD y PAVET DE COURTEILLE, vol. III, Paris, 1861, pp. 195-199. Véase ahora la nueva edición revisada y corregida por CH. PELLAT, vol. II, París, 1965, pp. 399-401.

(29) Cfr. S. PANTUČEK: Das Epos über den Westzug der Banü Hiläl, Praga, 1970, p. 59.

(30) Cfr. R. BASSET: Mille et un contes, récits et légendes arabes, Paris, 1926, p. 301. 
Dentro de este contexto social, y como una prueba más de la transferencia de leyendas y realidades históricas del mundo árabe al mundo occidental, hemos de situar, sin duda, el epíteto au Court Nez, de Guillermo de Orange de acuerdo con la tradición en que se desarrolla el poema. Si en la transmisión tradicional se ha diluido el motivo originario, resta en el Charroi de Nimes un recuerdo claro, ajeno por otra parte a las prácticas jurídicas occidentales, del significado infamante del tajo de la nariz. Cuando, en un intento de reconocimiento, el rey Otran de Nîmes cree ver a Guillermo de Orange en el supuesto mercader del carretaje, el conde cristiano da la siguiente explicación:

v. 1.232 «Sire, dist il, envers moi entendez.

De cele chose que vos ci demandez

vos dirai gé volantiers et de grez.

Quant je fui juenes, meschins et bachelers,

si deving lerres, mervelleus por embler,

et engingnierres; onques ne vi mon per.

Cupoie borses et gueilles bien fermez,

si m'en repristrent li mestre bacheler

si marcheant cui ge avoie enblé;

a los couteaus me creverent le née,

puis me lessierent aler a sauveté,

si commençait cest mestier que veez (31).

Naturalmente, la mutilación de la nariz, como penalidad del latrocinio, está dentro de la estructura sociológica del mundo musulmán y lejos de las tradiciones occidentales, to que prueba, sin duda, según indiqué anteriormente, la dependencia del poema francés.

Creo que estos ejemplos, asi como las afirmaciones generales que he hecho con anterioridad, son suficientes para reconocer hasta qué punto está arabizada la épica francesa.

Pasando ahora a otro género de la narrativa, el de los fabliaux, podemos, siempre a modo de ejemplo, analizar rápidamente los siguientes casos:

El eminente teólogo, pensador original, místico y reformador religioso Al-Gazāî, conocido en el mundo hispánico con el nombre de Algacel, recoge en el capítulo final, dedicado al «Amor de Dios», de su Kimmiya' al-sa'āda o la «Alquimia de la felicidad», un notable cuentecillo, sin duda de origen tradicional (32). Tal relato dice así, en traducción lo más literalmente posible:

"Cierto basurero o estercolero entró en la calle de los perfumistas, y, oliendo las dulces especias, cayó desmayado sin sentido. La gente acudió a su alrededor y roció su rostro con agua de rosas y aplicó el azmicle a su nariz, pero cada vez empeoraba su situación. Finalmente, pasó por allí un individuo, que en otro tiempo había sido él mismo basurero, colocó un poco de estiércol debajo de la nariz del hombre desmayado, y éste revivió instantáneamente, exclamando, con aspecto de satisfacción: ¡Por Dios! jésto es perfume de verdad!».

(31) Edición de G. DE POERCK y R. ZWAENEPOEL: Textes et traitement automatique, Pacy-sur-Eure, 1970.

(32) Para más detalles, véase ÁLVARO GALMÉS DE FUENTES: «Un conte de Al-Ghazāli et le fabliau français Du vilain asnierm, en Romance Philology, XXXIX, 1985, pp. 198-205. 
Este cuentecillo de Algacel, sin duda tradicional, ofrece una identidad temática con el fabliau francés Du vilain asnier. Es éste uno de los más cortos fabliaux, por lo que no necesito casi hacer un resumen para ver la correspondencia. He aquí el relato:

Ocurrió una vez en Montpellier que un villano, que acostumbraba a transportar estiércol con dos burros, entró un día en la ciudad, siguiendo a los asnos, que llegaron hasta la calle de los especieros o perfumistas. Cuando olió las especias cayó desmayado inmediatamente. La gente asustada no sabia que hacer, hasta que un buen hombre, que antes habia sido estercolero, dijo que lo curaría si le pagaban con buena moneda. Le pagaron veinte sueidos, y el buen hombre cogió una pala, la cargó con el estiércol que transportaban los asnos, y la acercó a la nariz del villano desmayado. Cuando éste sintió los efluvios del estiércol y perdió el olor de las hierbas, abrió los ojos, muy contento por haberse curado, y juró que jamás volvería a tal lugar.

El fabliau francés termina con una despiadada moraleja:

Et por ce vos vueil ge monstrer que cil fait ne sens ne mesure qui d'orgueil se desennature:

$\mathrm{Ne}$ se doit nus desnaturer.

La correspondencia entre ambos textos es evidente y no es preciso insistir en ella. Únicamente señalaré aqui que un detalle importante, común a los dos relatos, el de la calle de los especieros o "sūq al-'attārina» (la "rue as especiers» del texto francés) nos sitúa más en el contexto de una ciudad árabe que en el de una ciudad europea, por lo que parece obvia la dependencia del fabliau francés respecto al texto árabe.

En el plano sintáctico, el cuentecillo árabe, que proporciona la motivación o motivaciones de la acción o de las acciones, tiene el valor de una oración «atributiva», en la que el predicado sólo representa una cualidad del sujeto (el basurero está avezado de malos olores, lo que implica que los buenos olores le perturban y que sólo puede recobrar las fuerzas al experimentar de nuevo el olor del estiércol). El carácter «atributivo» del relato de Algacel viene puesto de relieve por la conclusión del mismo: «Por Dios! jésto es perfume de verdad!». $Y$ no hay otra deducción.

Frente a esta situación, el fabliau francés es un relato "predicativo», en el que se expresa un fenómeno, una transformación en la que el sujeto participa, que comporta un verbo transgredir, «transitivo» en relación al sujeto. Es decir, bajo el impacto de una serie de transformaciones (intensificación del motivo de los asnos, representación irónica del salvador), el fabliau francés; no se contenta, como el cuentecillo árabe, con descubrir una situación determinada, sino que aporta la «transgresión»: puesto que el basurero ha osado desviarse de su ocupación habitual, ha tratado de modificar su naturaleza, debe por ello sufrir un castigo, lo que se expresa claramente en la despiadada moraleja, que antes he citado.

En la colección de cuentos árabes titulada el Sendebar o Libro de los engaños aparece un cuentecillo, que indiscutiblemente está en relación con otro fabliau francés conocido por el título de Auberée, nombre de la alcahueta protagonista del relato (33). He aquí el argumento del relato árabe:

(33) Sobre este motivo véase un trabajo mio, más pormenorizado, «El Libro de los Engaños y el fabliau francés de Auberéen, en Homenaje al profesor Luis Rubio. 1, Universidad de Murcia, 1990, pp. 431-439. 
Un joven enamorado de una vecina recién casada acude a una alcahueta para conseguir sus pretensiones. La vieja le propone ir a la tienda del marido, que es mercader, para comprarle un paño especial que el comerciante tenía en gran estima. Una vez hecha la compra el joven llevó el paño a la vieja, que lo quemó en tres lugares. Con el paño debajo del brazo la alcahueta fue a casa de la mujer del comerciante, y hablando con ella metió el paño debajo de la almohada de la cama matrimonial. Cuando vino el mercader tomó la almohada para reposar sobre ella, y encontró el paño, pensando que el que lo compró era amigo de su mujer y que se le habia olvidado allí el paño. Se levantó el comerciante, golpeó a su mujer y la echó de su casa. Entonces cubrió su cabeza la mujer y se fue a la casa de sus parientes. La vieja alcahueta, que estaba al tanto, la fue a visitar, haciéndola creer que un hechizo era la causa de su mal, pero le da un buen consejo: «En mi casa hay un hombre - dice la vieja - de los sabios del mundo, que te curarás. Y llevó la alcahueta a la mujer del comerciante a su casa, y la metió en la habitación en que estaba el joven, que se dirigió a ella y yació con ella. Pero la mujer, con miedo y con vergüenza, se calló. Sin embargo, una vez satisfecho el deseo del joven, había que deshacer el entuerto, y la alcahueta ordena al joven que se haga el encontradizo con el comerciante al que compró el paño, «el cual - añadió la vieja - te llamará y te preguntará por el paño, a lo que tú deberás responder que lo pusiste cerca del fuego y se te quemó por tres lugares, por lo que lo diste a una vieja para que te lo zurciera, de la cual vieja no volviste a saber más». «Entonces - continúa la alcahueta - yo me haré la pasadiza por ese lugar, y di tú: -Aquella fue a la quien yo di el paño, y llámame, que te excusaré de todo». Lo hicieron así, y cuendo el joven llamó a la vieja ésta dijo al comerciante: «A buena fe, este mancebo me dio un paño para zurcir, y entré con él bajo mi manto en tu casa, y en verdad no sé si se me cayó alli o en la calle». A lo que repuso el comerciante: "Yo lo hallé; toma tu paño y vete en buena ventura». Entonces fue el mercader a su casa y envió a por su mujer, y la rogó que le perdonase, y ello lo hizo así (34).

El fabliau francés, emparentado con el cuento del Sendebar es un relato extenso de 666 versos, cuyo resumen es como sigue:

Un rico burgués de Compiègne ama a una joven vecina de escasa fortuna, por lo que el padre se opone a la boda. Mientras tanto la joven se casa con un viudo rico. Nuestro joven amante desesperado acude a la alcahueta, llamada Aubéree, oficialmente costurera. La vieja le promete al enamorado alguna entrevista galante con la muchacha, si aquél le deja su hermoso surcot, especie de chaleco o jubón. La vieja, provista del surcot va a casa de la joven esposa a la que entretiene con vana palabrería, hasta conseguir ser introducida en el dormitorio conyugal, donde coloca el surcot, junto con una aguja y un dedal, debajo de la colcha. Cuando el marido vuelve a casa, va a descansar a su cama, en donde encuentra el surcot. Este descubrimiento le hace pensar al marido en la infidelidad de su mujer. Ante estas sospechas, y sin mediar palabra, el marido echa a la calle a su mujer. Auberée, atenta a la situación, se hace la encontradiza con la joven esposa, y le ofrece su casa, en donde encontrará buena comida, buena habitación, y al galán que la esperaba:

Le vallet est au lit alez,

les la bourjoise s'est coulez.

Y la joven, con miedo y vergüenza, no protestó ni dijo nada.

Al cabo de dos dias, cuando suenan los maitines, Auberée acude al lecho en que yacen los amantes:

Or sus! fet ele, bele fille

si en irons a Seint Cornille.

(34) A. GONZÁLEZ PALENCIA: Versiones castellanas del «Sendebar», Madrid-Granada, 1946, pp. 37-40. 
En la abadía de Saint-Corneille ordena a la joven que se extienda en el suelo, delante de la imagen de la virgen, en actitud de oración, con una cruz a la cabeza y otra a los pies, y alumbrada alrededor por ocho gruesos cirios, y la conmina a que no se mueva hasta su vuelta.

La vieja corre a casa del marido, llama a la puerta, y cuando el burgués responde, le dice cómo su mujer lleva dos dias haciendo penitencia ante el altar de la virgen. El marido acude al monasterio, y se muestra muy satisfecho de que su mujer haya empleado tan piadosamente el tiempo. Pero aún persiste la duda: ¿de dónde procedía el surcot misterioso? Pero, cuando sale a la calle, todavía atormentado por la sospecha, oye lamentarse a Auberée:

\section{Trente solz, seinte voire Crois!}

Trente solz, dolente, chetive!

Y el burgués, al oír las lamentaciones, le pregunta por la causa, a lo que responde Auberée: «Un muchacho hace unos dias me trajo para zurcir un surcot, que había quemado en tres lugares, y yo lo llevaba bajo el manto cuando entré en tu casa a hablar con tu mujer y no sé donde lo he perdido, y ahora el muchacho me reclama una gratificación de treinta sueldos». El burgués, al escuchar estas palabras, entra en su casa, observa el surcot efectivamente agujereado, y con la aguja y el dedal dispuestos para zurcirlo. Así la vieja libró al burgués de sus malos pensamientos, y a todos tres sirvió amistosamente (35).

Como puede verse, a través de estos resúmenes, salvando algunos pequeños rasgos, la trama es idéntica en los dos relatos. Los detalles coincidentes, por otra parte, son tantos que no cabe pensar que ambas narraciones hayan surgido con independencia en Oriente y en Occidente. Ahora bien, como la versión árabe más antigua que conocemos es del sigio $X$, incluida, como indiqué anteriormente, en Las mil y unas noches, muy anterior, por tanto, al fabliau francés, el camino recorrido, lo que está, por otra parte, de acuerdo con la historia cultural, no es otro que el que va de Oriente a Occidente. No obstante esta comprobación no implica que el fabliau francés tenga que ser una deturpación del «original» árabe, como suponían para casos análogos J. Bédier y la crítica positivista. Por el contrario, es evidente que el autor del Auberée, en su nueva "escritura" del relato, ha conseguido una obra maestra. Como he señalado para el ejemplo anterior, un cuentecillo árabe «atributivo», se ha transformado en un bello relato «predicativo", en donde se encuentran reunidas las mejores características de los fabliaux: re-creación perfecta, desarrollo hábil de cada escena, manejo vivo del diálogo, relatos conseguidos y «petits faits vrais».

En otro caso, E. Laoust publica y traduce al francés un curioso cuento bereber, que por su brevedad puedo recordarlo aquí íntegramente:

Un hombre vivía con su mujer y un hijo pequeño del producto de la caza. Todos los dias cazaba tres perdices, la suya, la de su mujer y la del niño. Pero un día, sin embargo, capturó cuatro perdices, y cuando volvió a su casa se encontró ante su puerta un hombre que le pidió hospitalidad: «Seas el bienvenido, le dijo el cazador, la bondad te ha precedido generosamente». Entraron en la casa; la mujer peló las perdices, las limpió y las echó en la cazuela. El marido se levantó y dijo al forastero: "Vamos a rezar a la mezquita, mientras se prepara nuestra cena».

Cuando partieron, el niño se durmió en el regazo de su madre. Enseguida las perdices estuvieron guisadas. La mujer las retiró del fuego y permaneció a la espera de su marido y del huésped. Pero, como éstos tardasen, pensó para sí: «Mi hijo duer-

(35) Sigo la versión de GUY RAYNAUD DE LAGE: Choix de fabliaux, Paris, 1986, pp. 15-35. 
me, voy a comer su perdiz y la mia». Comió, pues, su perdiz y la de su hijo, y reservó las otras dos. Pero un poco después volvió a decirse a sí misma: «Sospecho que nuestros vecinos han retenido al huésped en su casa». Y comió, pues, su perdiz, reservando la de su marido. Al tardar este último en llegar, se dijo la mujer: «Sin duda ha ido a ver a su madre; es inútil esperarle». La mujer cogió su perdiz y la comió Al poco tiempo, el niño se despertó y comenzó a llorar, puesto que su madre no tenia nada que ofrecerle para comer. En esta situación, el invitado llegó, y, al observar al niño, preguntó a su madre: «¿Por qué llora?». «Según nuestra costumbre, dijo la madre, cuando un huésped nos visita le cortamos las orejas y se las damos al niño para que se calles. Al oír estas palabras, el huésped salió rápidamente y emprendió la huida. El marido entró a su vez, y, viendo que el niño lloraba, preguntó: "¿Qué le ocurre?». «El huésped se ha escapado con las perdices de nuestra cena», dijo la mujer. El hombre, al oír esta acusación, comenzó a perseguir al huésped: «Párate, por favor, le gritó, dame por lo menos una para el niño». No dudando que se refería a su oreja, el invitado corrió aún más, diciendo: «Si tú me alcanzas, eres capaz de cortarme las dos» (36).

Este cuento bereber de Marruecos es, sin duda, de origen árabe, como veremos más adelante. No obstante, sólo conozco una versión árabe moderna, también marroquí (37), pero que se presta menos a nuestro propósito que el cuentecillo bereber. Porque, lo que aquí me interesa, ante todo, es poner de relieve la identidad temática entre el cuento bereber y el fabliau, «Le dit des perdriz».

He aquí resumido el argumento del fabliau francés:

Un villano caza casualmente dos perdices. Se las da a su mujer para que las cocine, mientras él' va a buscar al párroco para invitarle a comerlas. Una vez guisadas las perdices, la mujer glotona no se resiste a probar algunos bocados, y después se asoma a la calle, y al comprobar que no aparecen el cura y su marido, acaba comiéndose íntegras las dos perdices. Al poco tiempo aparece el marido que pregunta por las perdices, a lo que le responde su mujer que, puesto que ya están guisadas, que coja el cuchillo y salga al patio a afilarlo para poderlas trinchar cómodamente. Mientras tanto aparece el cura, que abraza dulcemente a la mujer, y ésta le dice: "Señor, huya, huya; vea a mi marido que está en el patio, afilando el cuchillo, para cortarle los testículos». Ante esta amenaza el cura sale corriendo, mientras la mujer llama a su marido para decirle que corra tras el cura, que ha robado las perdices. El marido, con el cuchillo en la mano, corre detrás del cura. Cuando éste ve detrás de si al villano, no duda de las intenciones denunciadas por la mujer y arrecia la carrera hasta esconderse en el monasterio (38).

Al establecer una relación entre diferentes textos, es preciso distinguir dos planos diferentes; de un lado, la «estructura implícita», la «estructura narrativa profunda» o el «tema», y, de otro lado, la «manifestación de la estructura», las «unidades semánticas manifestadas» o el "desarrollo narrativo», según la terminología que se quiera adoptar. Es evidente, que en lo que se refiere al primer plano (la estructura implícita, la estructura narrativa profunda o el tema) los dos relatos (el del cuentecillo bereber y el del fabliau francés) son idénticos, lo que asegura la relación de casualidad.

Ahora bien, frente al cuento árabe y bereber, el fabliau francés intensifica irónicamente los rasgos de la mujer, que conducen a una despiadada moraleja antifeminista:

(36) E. LAOUST: Contes berbères du Maroc, Paris, 1949, pp. 56-57.

(37) G.S. COLIN: Chrestomatie marocaine, Paris, n. XXVII, p. 12.

(38) Sigo la edición de GUY RAYNAUD DE LAGE: Choix de fabliaux, París, 1986, pp. 93-98. 
150 Par essample cis fabliaus dist: fame est fete por decevoir, mençonge fet devenir voir et voir fet devenir mençonge.

$Y$ aquí está la diferencia sustancial entre los distintos relatos. Como ya he señalado anteriormente, la narrativa árabe como, por ejemplo, los cuentos de Las mil y una noches, es, generalmente, «asicológica» y se caracteriza por su valor «atributivo». Tal es el caso del cuento árabe y bereber, que ahora nos ocupa. En el plano sintáctico, que realiza la motivación de la acción, el cuento bereber tiene el valor de una cualidad del sujeto. Frente a esta situación, el fabliau francés es un relato «predicativo», en el cual se expresa un fenómeno, una transformación, en la que el sujeto participa, y que comporta un verbo transgredir, «transitivo» en relación al sujeto. Es decir, que bajo una serie de transformaciones (intensificación del carácter de la mujer, glotona y lujuriosa, amante del cura), el fabliau francés se convierte en la historia de una «transgresión»; no se contenta, como en el cuento árabe y bereber, con describir una situación determinada, sino que aporta la idea de la «transgresión», tal como se refleja claramente en la implacable moraleja (39).

En todo caso, jcuán lejos de la realidad J. Bédier atribuía nuestro fabliau a la inventiva de los goliardos, creyendo ver en él claras reminiscencias monacales! (40).

Finalmente, y para terminar, quisiera traer aquí todavia un ejemplo que estimo singular, el del bellísimo lai francés del Oiselet. Sabido es que los lais franceses, sin ninguna restricción, son considerados, en conjunto, como pequeñas narraciones procedentes de la materia bretona, es decir, viejas reliquias del folclore celta. Así, por ejemplo, R. Bossuat, en su célebre manual de bibliografía de la literatura francesa medieval, bajo los epígrafes, «Marie de France et les lais bretons» y «Lais bretons anonymes ou d'attributions diverses", analiza los trabajos sobre estos temas, en donde no faltan naturalmente, referencias a nuestro «lai de l'oiselet» (41). De forma semejante Lagarde y Michard afirman de modo general: «L'intérêt de les lais est, pour nous, de rester plus proches du fantastique primitif, issu de l'âme réveuse des Celtes et des Gallois» (42).

Pues bien, veamos que hay de ese espíritu soñador de los celtas y de los galos en nuestro Lai de l'oiselet.

El escritor hispano-musulmán al-Šariši (1161-1223), autor de un famoso Comentario de las Macamas de Hariri, nos ofrece la brevísima versión de un cuento, que traducido, lo más literalmente posible, dice así:

Un hombre cazó una alondra. — ¿Qué te propones hacer conmigo?», preguntó ella. - "Yo te mataré y te comeré», respondió. - «Por Dios, yo no serviré para engordarte ni para calmar tu apetito. Si tú quieres, en cambio, yo te enseñaré tres máximas

(39) Para más detalles, podrá verse ÁLVARO GALMÉS DE FUENTES: «Un cuento bereber y el fabliau francés Le dit des perdriz", en Homenaje a Luis L. Cortés Vázquez, Salamanca (en prensa).

(40) J. BÉDIER: Les fabliaux. Études de littérature populaire et d'histoire de moven âge, 7. a ed., Paris, 1969, p. 398.

(41) R. BOSSUAT: Manuel bibliographique de la lettérature française du moyen âge, Nedeln/Liechtenstenin, 1971, pp. 140 ss. y 144 ss.

(42) A. LAGGARD y L. MICHARD: Moyen Âge (Les grands auteurs français), I, Paris, 1968, p. 45. 
que te serán más útiles que el comerme. De esta forma, yo te diré la primera cuando esté todavia en tu mano; la segunda cuando esté encima del árbol, y la tercera cuando esté encima de la montaña». Dijo el hombre: - «De acuerdo». La alondra, que el cazador tenia en la mano dijo entonces: - «No deplores lo que se te ha escapado». Al instante el cazador soltó la alondra. Cuando estuvo encima del árbol, dijo: - «No creas lo que no puede serm. Cuando la alondra finalmente ganó la cima de la montaña, gritó: - «Desgraciado, si tú me hubieras matado, habrias encontrado en mi molleja una perla que pesa veinte onzas». Al oír estas razones, el cazador se mordió los labios, lanzó un suspiro y dijo al pájaro: -«Dame la tercera máxima». Dijo la alondra: - «Tú has olvidado ya la dos primeras». Dijo el hombre: —¿Cómo es eso?». Contestó el pájaro: - «No te dije yo que no lamentases lo que se te ha escapado? Ahora bien, tú deploras el haberme perdido. Yo te he dicho igualmente: no creas lo que no puede ser, y sin embargo tú has creido lo que te he dicho, sin tener en cuenta que todo mi cuerpo -carne, huesos y plumas - no alcanzaría el peso de veinte onzas; ¿cómo, pues, podría haber en mi molleja una perla de tal peso?».

Pues bien, el Lai de l'oiselet, con deliciosas amplificaciones referidas a la descripción del jardín en el que canta el pájaro, al canto mismo de los pájaros, reproduce con total fidelidad el relato del cuentecillo árabe. Si suprimimos del lai francés las referidas amplificaciones, éste quedaría reducido a los siguientes términos:

1 II avint jadis a un tans,

3 qu'il estoit uns riches vilains;

9 il avoit un manoir, si bel.

20 Et li vergiers qui fu de pris estoit d'arbres et d'eaue enclos.

29 Li vergiers fu beaus a devise:

74 Chanter i venoit uns oiseaus.

$126 \mathrm{Li}$ vilains cui li estres fu i venoit deus fois par costume por oir cele soatume.

196 Et li vilains, qui remest la, pense se il le pooit prendre.

200 En jaiole le meteroit, si li chanteroi tart et tempre.

214 «Tel loier a qui vilain sert fait li oiseaus, ce m'est avis: Mal avés fait qui m'avés pris»

218 - «Ains en avrai mainte chançon, fait li vilains, de ceste prise». 
233 - «Ja en prison ne chanterai». — «Par foi, et je vos mangerai

236 - «En moi povre repast avrés, quar je sui lasches et petis;

252 «mais se vos me laissiés aler. de trois sens vos ferole sage».

257 - «Se seürté en puis avoir, fait li vilains, tost le feraì. - «Tel fiance come je ai, fait li oiseaus, vos en creants. Et cil le lait aler a tant.

Li oiseaus sor l'arbre s'en vole.

271 Si le dist: - «Se tu bien entens, aprendre porras un grant sens: Ne croi pas quant que tu os dire"

288 «Li autres est et bons et beaus: Ne pleure pas ce qu'ainc n'éüs". Li vilains ne fu mie mus, ains respondi par felonie: - «Tu m'as ta fiance menti.

330 Et quant li oisillons l'entent, si dit: - «Je te chasti, vilains, que se que tu tiens en tes mains ne gietes pas jus a tes piés». Li vilains fu mout corrociés:

342 De quant que m'avés ensegnié estoie je sages devant». $\mathrm{Li}$ oiseaus respont maintenant: «Par foi, se tu cel sen seüsses, ja laissié aler ne m'eüsses; quar si tu m'eüsses tué,

353 tu ne sés qu'il t'est avenu:

355 Il a en mon cors une pière, qui tant est precieuse et chière, bien est de trois onces pesans».

362 Quant li vilains entendi ceste, debat son pis, deront ses dras.

366 Li oiseaus en fait grant leece, qui de sor l'arbre l'esgardoit; 
371 puis lui a dit: "Chetis vilains, quant tu me tenis en tes mains g'ière plus legiers d'un moisson,

375 qui ne poise pas demie once».

382 «Vilains, or en droit prové t'ai de cel sen que pas nel savoies".

401 Quant ce out dit, si s'en vola et de tel eür s'en ala, qu'ainc puis el vergier ne revint

409 Li proverbes dit en apert:

Cil qui tot convoite tot pert (43).

Como siempre el relato francés añade una sentencia moral, con lo que convierte la narración árabe simplemente «atributiva» en «predicativa». Sin embargo, el cúmulo de coincidencias es tan grande que, en ningún caso, puede pensarse en un fenómeno poligenético. Pero es que además el cuentecillo árabe lo encontramos en otros textos románicos, estrechamente vinculados con la narrativa oriental. Así, aparece en la Gesta Romanorum (n. 167 de la edición de Oesterley), compuesta en Inglaterra en el siglo XIII y que contiene tantos elementos del folclore oriental, en la Disciplina Clericalis (n. 22), en el Libro de los enxenplos (ns. 53 y 300) y en el Barlaam y Josafat (p. 345 de la edición de Gayandos), los tres últimos de origen árabe en su totalidad, y finalmente en el Caballero Cifar ( $p .259$ de la ed. de Charles P. Wagner), muy impregnado de narrativa árabe.

En todo caso, en lo que se refiere al origen de los lais franceses, hemos de poner en tela de juicio supuestos generalizados. Frente a vagas afirmaciones como la del «alma ensoñadora de los galos», antes citada y que, sin duda, encierra grandes dosis de chauvinismo, yo pediría a los celtistas ejemplos concretos del folclore de los galos, que puedan ser objeto de comparación, como el cuentecillo árabe, que ahora he traído aquí y al que podría añadir otros varios, porque de lo contrario se exponen los celtistas a que desaparezca en sueños el espíritu de los galos, en pro del influjo del folclore árabe.

En conclusión: los ejempios que he recordado aquí, aunque pocos por razón de la brevedad, creo que son suficientes para poner de relieve dos circunstancias importantes de la actividad literaria francesa de la edad media:

- En primer lugar, la fuerte impronta árabe en la literatura de allende el Pirineo, pues en la edad media, especialmente hasta el siglo XIII, como recordaba al principio, nuestro mundo occidental estaba inmerso en el área cultural del mundo árabe, entonces superior a la europea, y no podemos olvidar a este respecto la afirmación de $P$. Zumthor, según la cual «la vitalité, l'avidité et la mobilité intellectuelle de l'esprit médiéval associent, en fait, à l'exploitation systémati-

(43) Edición de G. PARIS: Légendes du Moyen Âge, Paris, 1904, pp. 274-291. 
que des legs du passé, une grande perméabilité aux influences exotiques les plus diverses» (el subrayado es mío) (44).

En segundo lugar, hemos visto que la capacidad re-creadora de la inventiva francesa supo admirablemente asimilar, y ese es sin duda su mayor título de gloria, los materiales extraños, constituyendo con ellos, en una nueva «escritura» aplicada a su propio intento, los géneros autóctonos nacionales de la epopeya, del fabliau o del lai, porque, como ha señalado T. Todorov (45), es en la «escritura» en donde se crea la unidad; los motivos que el análisis de los temas folclóricos nos dan a conocer, son transformados por la «escritura» del autor de los cantares de gesta, de los fabliaux y de los lais. Y es precisamente a través de estas transformaciones como podemos captar mejor las leyes que rigen la unidad de los distintos relatos. Del mismo modo, que una palabra extranjera incorporada a otra lengua deja de ser extranjera, bajo el efecto de las necesarias transformaciones fonéticas y morfológicas, de las cuales se deducen más claramente las leyes del vocabulario (46), así los relatos árabes incorporados, a través de las transformaciones analizadas, a la narrativa francesa se integran plenamente, por la nueva «escritura», a las leyes que gobiernan el universo narrativo de la literatura francesa medieval.

(44) P. ZUMTHOR: Essai de poétique médiévale, Paris, 1972, p. 75.

(45) T. TODOROV: Grammaire du Décameron, La Haye-París, 1969, p. 12.

(46) loid, p. 25 